\title{
Desafios do ensino remoto para surdos no período da COVID-19
}

\author{
Carla Alcyone da Silva Almeida \\ Universidade Estadual do Ceará ${ }^{1}$ \\ Germana Maria de Araújo Lima Rodrigues \\ Universidade Estadual do Ceará ${ }^{2}$
}

Resumo: Com a chegada da Pandemia da COVID-19 ao Ceará, o Instituto Cearense de Educação de Surdos (ICES) viu-se em uma situação desafiadora para garantir o acesso e a permanência dos educandos por meio do ensino remoto. Este o artigo objetiva analisar os desafios no processo de escolarização dos estudantes surdos, do sexto ano, do ICES, no ensino remoto, no período da pandemia, em 2020. O percurso metodológico foi realizado por meio da pesquisa bibliográfica e do relato de experiência de umas das autoras do artigo, enquanto professora surda do ICES. Observouse que para desenvolver uma nova forma de ensino que contribuísse para a formação da identidade, da cidadania e para a garantia do direito à educação aos surdos, foi necessária a parceria entre comunidade escolar, família e Estado. Ademais, espera-se que esta pesquisa possibilite novos caminhos a outros pesquisadores e docentes juntos aos alunos surdos.

Palavras-chave: Política de Educação. Surdos. Pandemia da COVID-19.

\section{Remote Education Challenges for the Deaf During Covid-19 Pandemic}

\begin{abstract}
The Ceará Institute of Education for the Deaf (ICES) was posed with a challenging situation with the arrival of Covid-19 pandemic to assure the access and the permanence of its students through remote teaching. Thus, this article aims to analyze the difficulties found in the educational process of deaf sixth graders at ICES concerning their remote education during the pandemic. The methodological path is made of bibliographical research and an experience report from one of the article's authors as a deaf teacher at ICES. The research revealed that to develop a new teaching method, one that would contribute to the construction of the identity and citizenship of the deaf assuring them the right to education, the partnership between school community, family and the State was fundamental. We hope this work may belp other researchers and teachers trace new paths alongside deaf students.
\end{abstract}

Keywords: Education Policy. Deaf Person. Covid-19 Pandemic.

\footnotetext{
1 Mestranda em Serviço Social (Mestrado Acadêmico em Serviço Social, Trabalho e Questão Social da Universidade Estadual do Ceará, graduada em Serviço Social pela Universidade Estadual do Ceará). ORCiD: https://orcid.org/0000000175986829.E-mail: carla.alcyone@aluno.uece.br.

2 Mestranda em Serviço Social (Mestrado Acadêmico em Serviço Social, Trabalho e Questão Social da Universidade Estadual do Ceará, graduada em Letras - Libras pela Universidade Federal do Ceará. ORCiD: https://orcid.org/0000-0001-6339-0307. E-mail: germana.maria@aluno.uece.br.
}

Cadernos GPOSSHE On-line, Fortaleza, v. 5, n. 1, 2021

https://revistas.uece.br/index.php/CadernosdoGPOSSHE

DOI: $10.33241 /$ cadernosdogposshe.v5i1

ISSN: $2595-7880$ 


\section{INTRODUÇÃO}

A pandemia do novo Coronavírus (SARS-CoV-2), causador da doença COVID-19, desde 2019, tem provocado uma crise sanitária, econômica, social e educacional sem precedentes. Atualmente, no Brasil, de acordo com o Ministério da Saúde, em 02 de agosto de 2021, tinha-se contabilizados 19.953 .50 milhões de casos confirmados e mais 557 mil óbitos.

Diante da seriedade dessa doença, para conter o avanço da transmissão do vírus, a Organização Mundial da Saúde (OMS) recomendou o distanciamento social e uso de máscaras. Tais orientações culminaram também na suspensão de aulas presenciais nas escolas e, consequentemente, na substituição por aulas remotas.

Dados da UNESCO (2020) demonstram que a crise de saúde causada pela COVID19 resultou no fechamento de escolas e universidades, afetando mais de $90 \%$ dos estudantes do mundo. Essa realidade apresenta-se mais preocupante quando se analisa a situação dos educandos com deficiência e da comunidade surda, visto que, em virtude das diversas barreiras sociais, têm o acesso e a permanência na escola mais dificultadas.

Diante dessa problemática, o artigo tem como objetivo geral analisar os desafios no processo de escolarização no ensino remoto, dos estudantes surdos, do $6^{\circ}$ sexto ano, do ensino fundamental II, do Instituto Cearense de Educação de Surdos (ICES), no período da Pandemia da COVID-19. Para isso, foram elencados os seguintes objetivos específicos: apresentar as categorias deficiência, educação para surdos e política de educação enquanto expressões da questão social; realizar um breve histórico sobre a educação de surdos e discorrer sobre os desafios da escolarização dos educandos, do sexto ano, do ICES, durante o ensino remoto. Tais objetivos específicos transformaram-se nas subdivisões do presente trabalho.

Para o percurso metodológico, foi utilizada a pesquisa bibliográfica que, por meio de leitura de artigos e livros de autores como Maior (2015), Strobel (2006), Cunha (2021), Lacerda (1998), entre outros. A presente pesquisa, de natureza qualitativa, utiliza também o relato de experiência, a partir da vivência de uma das autoras, que é professora surda do sexto ano do ICES. 


\section{DEFICIÊNCIA, EDUCAÇÃO PARA SURDOS E POLÍTICA DE EDUCAÇÃO COMO QUESTÃO SOCIAL}

Historicamente, as pessoas com deficiências e a comunidade surda enfrentam a eliminação, a exclusão e a segregação como forma de preconceito e de discriminação em virtude da supervalorização da capacidade física, sensorial e cognitiva na sociabilidade capitalista (MAIOR, 2015).

A sociedade capitalista almeja um sujeito ideal que seja útil à lógica de produção de mercadoria e de lucros. Aqueles corpos identificados como desviantes, como os das pessoas com deficiência (dentre elas, as da comunidade surda) são segregados ou inseridos em uma lógica que busca a correção dos desvios, pois não servem como mão de obra (CUNHA, 2021).

Diante disso, a deficiência é compreendida como expressão da questão social, visto que, em muitos momentos, ela é vista como uma questão de desvantagem social diante das barreiras sociais, as quais são consequências da pobreza e de outros fatores sociais resultantes da relação capital e trabalho. Tornando, com isso, a experiência das pessoas com deficiência desigual ao ser relacionada com as pessoas sem deficiência (CUNHA, 2021).

Como expressa Iamamoto (2001), a questão social faz referência ao conjunto das manifestações das desigualdades engendradas na sociedade capitalista madura, não podendo ser pensada sem a intervenção do Estado. Tem sua gênese no caráter coletivo da produção e a apropriação privada pelos donos dos meios de produção. Está indissociável da sociabilidade capitalista fundada na exploração do trabalho, que a reproduz de forma ampla.

Falar em questão social significa também compreendê-la como uma arena de lutas, políticas e culturais, pela classe trabalhadora contra as desigualdades socialmente produzidas (IAMAMOTO, 2008). Nessa lógica capitalista, busca-se a adequação dos corpos das pessoas com deficiência, das mais variadas formas, influenciado, a partir disso, o modo de compreensão e intervenção nas deficiências. Estas já tiveram diversas conceituações, desde “o entendimento como tragédia pessoal, passando pelas práticas biomédicas de correção de desvios, até a ruptura que considera contextos sociais" (CUNHA, 2021, p. 307). 
Maior (2015) explana sobre as duas principais concepções que influenciaram o conceito de deficiência do decorrer da história. Na primeira metade do século XX, surgiu o modelo biomédico da deficiência, que tinha como foco as limitações funcionais, desconsiderando as condições do contexto social. Para essa concepção, a deficiência era interpretada como incapacidade a ser superada e integrada ao social. A integração da pessoa com deficiência deveria ser alcançada a partir do esforço do indivíduo e da família, sem a necessidade de mudar a sociedade.

A partir da década de 1960, com a consolidação dos estudos sobre a deficiência e o movimento de reivindicação de direitos tendo como protagonistas as pessoas com deficiência e suas famílias, surgiu o modelo social da deficiência. Para essa concepção, o foco está nas condições de interação entre a sociedade e as pessoas com deficiências. Estas passaram a ser reconhecidas como sujeitos de direito com autonomia e independência para fazer escolhas. A partir dessa concepção, fala-se em inclusão, por meio do Estado, através das políticas públicas e não mais de integração.

Isso mostra que é com a efervescência das refrações na questão social que surge a necessidade de estruturação de políticas sociais pelo Estado enquanto instrumento de enfrentamento das desigualdades (CUNHA, 2021). Na perspectiva crítica, as políticas sociais devem ser analisadas como "processos e resultado de relações complexas e contraditórias que se estabelecem entre Estado e sociedade civil, no âmbito dos conflitos e lutas de classes que envolvem o processo de produção e reprodução do capitalismo" (BEHRING, 2006, p. 04). A referida autora argumenta que as condições históricas e sociais das políticas sociais devem ser extraídas do movimento da sociedade burguesa e das manifestações particulares dos Estados Nacionais.

No ponto seguinte será explicitado sobre como a educação da comunidade surda foi implementada ao longo da história enquanto manifestação da questão social.

\subsection{Breve histórico sobre a Educação dos surdos}

Da antiguidade até a idade média, devido à ausência de trabalho, pesquisa e incentivos estatais e particulares na área educacional, os sujeitos surdos eram estereotipados como 
“anormais". Era um período em que não havia escola para esse público, visto que não acreditavam na capacidade dos surdos. Na referida época, para ser considerado "normal" e ser aceito, era preciso falar e ouvir. Diante disso, a comunidade surda foi excluída da vida social e educacional (STROBEL, 2006).

Somente no século XVI observa-se o interesse de pedagogos em trabalhar a educação para os surdos. A premissa, nesse momento, era encontrar formas para que esse público pudesse se comunicar com o mundo ouvinte. Esses estudos e pesquisas eram realizados, muitas vezes, de forma secreta e destinadas, principalmente, para as famílias abastadas (LACERDA, 1998).

A autora acrescenta, que a partir desse período, já apareciam, nas propostas educacionais vigentes aos surdos, iniciativas que antecederam o que, a partir do século XVIII, ficou conhecidos como "oralismo" e "gestualismo". Para os defensores do "oralismo", como Heinicke, criador do "método alemão", o pensamento só é possível através da língua oral. Para os oralistas, os surdos deveriam ser reabilitados, superar a surdez, tentar falar como os ouvintes e não se comportarem como surdos. Já os gestualistas, tendo como principal representante o abade Charles M. de L' Epée, o primeiro a estudar a língua de sinais usadas e criador do "método do francês" e dos "sinais metódicos", verificou que os surdos desenvolviam um tipo de comunicação apoiada no canal viso-gestual, o qual era muito satisfatória. (LACERDA,1998).

O ensino da língua de sinais do Brasil teve grande influência da Método Francês, o nosso alfabeto manual é muito semelhante ao do país europeu. No Brasil, o ensino de surdos começou a existir em 1855 com a chegada do educador francês Hernest Huet no referido ano. Ele e o imperador D. Pedro II fundaram, em 1857, o Imperial Instituto de Surdos Mudos, atual Instituto Nacional de Educação de Surdos (INES). Ainda sobre o Brasil, em 1873, surge o documento "Iconographia dos Signaes dos Surdo-Mudos", um dos mais importantes registros sobre a Língua Brasileira de Sinais, de autoria do aluno surdo Flausino José da Gama (SOUZA, 2018). 
No final do século XIX, com o Congresso Internacional de Milão³, em 1880, termina uma época de convivência tolerada na educação entre linguagem falada e gestual. Como resultado deste evento, o uso da língua de sinais foi definitivamente banido a favor do oralismo, fato que oprimiu não apenas uma língua, mas uma cultura por mais de cem anos (FERNANDES; MOREIRA, 2014).

Acrescenta-se que até o século XIX, o atendimento à população surda era feito de forma filantrópica e assistencial. Os sujeitos surdos eram entregues às instituições de asilo, em regime de internato, até que estivessem aptos a retornar ao convívio familiar e social. Nesse período, em decorrência do avanço dos estudos da Medicina sobre os graus de surdez, os surdos também passaram a ser considerados “doentes" e "deficientes" (STROBEL, 2006).

No século XX, buscou-se resgatar os surdos para o convívio social enquanto sujeitos que mereciam a atenção educacional organizada. Com isso, houve o florescimento do ouvitismo científico, em especial na Medicina, com ênfase no processo clínico e de reabilitação dos surdos enquanto deficientes (STROBEL, 2006).

No Brasil, no século XX, especificamente, em 1951, ocorreu a regulamentação do ensino do curso normal de formação de professores para surdo-mudo. O objetivo era a alfabetização da comunidade surda em todo território nacional, tendo como base o oralismo (SOUZA, 1999 apud SOUZA, 2018).

No estado do Ceará, foi criado, em 25 de março de 1961, o Instituto Cearense de Educação de Surdos (ICES). A história do Instituto começou a partir da intenção de Hamilton Cavalcante ${ }^{4}$ em fundar uma instituição que viesse a atender pessoas com surdez. (SECRETARIA DA EDUCAÇÃO DO CEARÁ, 2016).

$\mathrm{Na}$ metade do século XX, o descontentamento com o oralismo e o avanço das pesquisas sobre as línguas de sinais, como os estudos do Willian Stokoe, sobre a língua de

\footnotetext{
3 “Em 1880, foi realizado o Congresso Internacional de Milão, Itália, para discutir o futuro da educação para os surdos e para avaliar o mérito de três métodos rivais: Língua de sinais, oralista e mista (língua de sinais e a falada). No dia 11 de setembro de 1880, houve uma votação de 160 votos a favor do método oral na educação de surdos e quatro votos contrários” (STROBEL, 2006, p. 249).

${ }^{4}$ Hamilton Cavalcante é professor das duas universidades públicas do Estado do Ceará, a Universidade Estadual do Ceará (UECE) e Universidade Federal do Ceará (UFC), na área de Linguística, e foi a partir de suas vivências no Instituto Nacional de Educação de Surdos (INES), ainda como estudante, que surgiu a ideia da criação de um mesmo espaço no Ceará. O ICES é, atualmente, a única instituição pública cearense destinada exclusivamente para a educação dos surdos. (SECRETARIA DA EDUCAÇ̃̃̃O DO CEARÁ, 2016)
}

Cadernos GPOSSHE On-line, Fortaleza, v. 5, n. 1, 2021

https://revistas.uece.br/index.php/CadernosdoGPOSSHE

DOI: $10.33241 /$ cadernosdogposshe.v5i1

ISSN: $2595-7880$ 
sinais americana, na década de 1960, ganha impulso, principalmente, nos anos 1970 e 1980, nos Estados Unidos, a chamada "comunicação total". Segundo Moura (1993 apud LACERDA, 1998, p. 06), esta técnica

[...] pode utilizar tanto sinais retirados da língua de sinais usada pela comunidade surda quanto sinais gramaticais modificados e marcadores para elementos presentes na língua falada, mas não na língua de sinais. Dessa forma, tudo o que é falado pode ser acompanhado por elementos visuais que o representam, o que facilitaria a aquisição da língua oral e posteriormente da leitura e da escrita

Lacerda (1998) explicita que importância da comunicação total foi possibilitar o retorno do contato com a língua de sinais, até então proibida pela prevalência do oralismo. A autora acrescenta que paralelo aos estudos desta proposta, surgiram, também, alternativas educacionais orientadas para a educação bilíngue dos surdos.

Hoje, no Brasil, a ideia da educação de surdos é voltada ao bilinguismo. A Libras é considerada a língua natural do surdo brasileiro e, por meio dessa, é capaz de expressar tudo que uma língua oral manifesta. Para o modelo bilíngue, segundo Lacerda (1998, p. 07),

[...] o que se propõe é que sejam ensinadas duas línguas, a língua de sinais e, secundariamente, a língua do grupo ouvinte majoritário. A língua de sinais é considerada a mais adaptada à pessoa surda, por contar com a integridade do canal viso gestual. Porque as interações podem fluir, a criança surda é exposta, então, o mais cedo possível, à língua de sinais, aprendendo a sinalizar tão rapidamente quanto as crianças ouvintes aprendem a falar. Ao sinalizar, a criança desenvolve sua capacidade e sua competência linguística, numa língua que lhe servirá depois para aprender a língua falada, do grupo majoritário, como segunda língua, tornando-se bilíngue, numa modalidade de bilingüismo sucessivo. Essa situação de bilingüismo não é como aquela de crianças que têm pais que falam duas línguas diferentes, porque nesse caso elas aprendem as duas línguas usando o canal auditivo-vocal num bilingüismo contemporâneo, enquanto no caso das crianças surdas, trata-se da aprendizagem de duas línguas que envolvem canais de comunicação diversos.

No Brasil, a partir do século XXI, com a Constituição Federal de 1988, que configurou um novo estatuto jurídico para o país, com os estabelecimentos de políticas sociais inclusivas, observam-se diversos avanços legislativos para a educação dos surdos, especificamente nos artigos 205 e 208, que expressa que é dever do Estado garantir a educação especial. Outro avanço está na Lei de Diretrizes e Base (LDB) da educação em seus 
$\operatorname{artigos} 4^{\circ}, 58^{\circ}, 59^{\circ}$ e $60^{\circ}$, os quais também explicitam sobre o papel do Estado na educação especial.

Cita-se também, nesse contexto, a Lei de $\mathrm{n}^{\circ}$ 10.098/2000, que assegura a acessibilidade para as pessoas com deficiência. Em seu artigo 18, expressa que o poder público irá implementar a formação de profissionais intérpretes de linguagem de sinais. Além disso, outras conquistas foram: a Lei n 10.436/2002, a qual dispõe sobre a Língua Brasileira de Sinais, regulamentada pelo Decreto $\mathrm{n}^{\circ}$ 5.626/2005; a Lei $\mathrm{n}^{\circ}$ 12.319/2010, que regulamenta a profissão de tradutor e intérprete de libras e a Lei $n^{\circ} 13.146 / 2015$, a qual promulgou a lei brasileira de inclusão.

No entanto, é importante ressaltar que desde a década de 1990, o Brasil vive uma contradição no campo dos direitos: de um lado, há o estabelecimento constitucional de políticas universais (educação e saúde) que supõe a intervenção estatal; de outro, há o contexto de instauração de um Estado Neoliberal, não interventor e que se adequa ao mercado mundial globalizado, com retração de direitos sociais (KASSAR, 2011).

Diante disso, observa-se, para a comunidade surda, em tempos normais, o avanço legislativo no reconhecimento de sua cultura e identidade pelo uso da Língua Brasileira de Sinais-Libras. Mesmo assim, ainda são reduzidos os espaços educacionais e comunitários que fomentem a existência da comunidade linguística em Libras. O que se observa é a utilização da Libras como uma tecnologia assistiva ${ }^{5}$ para tentar adaptar a escola regular para as pessoas surdas (FERNANDES; MOREIRA, 2014). Tais desafios mostraram-se agudizados neste período de Pandemia da COVID-19.

\subsection{O desafio do ICES na escolarização dos alunos surdos, do sexto ano, no ensino remoto, no período da Pandemia da COVID-19}

Com a chegada da Pandemia da COVID-19 ao Ceará, o Instituto de Educação de Surdos do Ceará (ICES) viu-se em uma situação inusitada. No dia 18 de março de 2020, o

\footnotetext{
${ }^{5}$ A Tecnologia Assistiva é um fator ambiental e inclui produtos e tecnologias para uso pessoal na vida diária, facilitação da mobilidade e transporte pessoal, comunicação, educação, trabalho, cultura, atividades recreativas e desportivas, prática religiosa e espiritualidade e arquitetura. É também reconhecida como elemento chave para a promoção dos direitos das pessoas com deficiência, garantido desde a promulgação do Decreto ${ }^{\circ} 3.298$ de 1999, que conceitua e lista as "ajudas técnicas" previstas para concessão (VARELA; OLIVER, 2013).
}

Cadernos GPOSSHE On-line, Fortaleza, v. 5, n. 1, 2021 
Governo do Estado do Ceará decretou lockdown ${ }^{6}$ e suspendeu todas as atividades presenciais no estado. Os profissionais do ICES viram-se, então, desafiados a lidar com a situação apresentada. Diante desse contexto, foi necessário realizar muitas adaptações, replanejar a forma de ensino e, especialmente, incluir no trabalho pedagógico o ensino remoto. O uso de novas tecnologias se tornou necessário.

Informa-se inicialmente, que nesse espaço, a língua usada em sala de aula é a Libras (Língua Brasileira de Sinais) como primeira língua e a Língua Portuguesa pela via escrita como segunda língua. Esse método é primordial na educação de surdos. Dada a circunstância imposta pela pandemia, fez-se necessário repensar o sistema de educação para surdos e buscar melhorias diante desse novo contexto.

Devido à necessidade de usar novas tecnologias, como aulas em chamadas de vídeos e aulas previamente gravadas para se adaptar ao ensino remoto, e mesmo já tendo acesso aos equipamentos eletrônicos (celulares, tablets e notebookss), a equipe de professores teve um grande desafio: fazer reajustes nos seus planos de aula e se familiarizar com as novas ferramentas de ensino, priorizando o uso de Libras durante as aulas. Vale destacar que o uso de Libras em sala de aula já era prioridade antes da pandemia.

A equipe de professores e a equipe pedagógica buscaram estar sempre em contato com os familiares para ter apoio mútuo e evitar evasão escolar. Para auxiliar no processo de aprendizagem e outras necessidades das famílias, a gestão do ICES realizou entregas de chips, com acesso à internet, e de cestas básicas aos alunos.

Para garantir a efetivação do ensino, muitos profissionais, no início da pandemia, por terem que trabalhar em casa, não tiveram o imediato aparato estatal. Devido a isso, esses funcionários tiveram que adquirir, a partir de meios próprios, instrumentos de trabalho como: celular, computador, energia, internet, entre outros.

Antes da pandemia, o Instituto já contava com uma equipe de intérpretes de Libras, obedecendo a Lei $n^{\circ} 10.436$, a qual reconhece a Libras como meio legal de comunicação das comunidades surdas brasileiras, regulamentada pelo Decreto ${ }^{\circ}$ 5.626. Entretanto, durante a

\footnotetext{
${ }^{6}$ Lockdown é um protocolo de emergência que se destina a prevenir a mobilidade de pessoas ou o vazamento de informações de uma área específica, que deve ser iniciado por alguma pessoa em condição de autoridade. Pode ser traduzido como fechamento, bloqueio ou suspensão e tem múltiplas interpretações e utilidades (NEVES, 2020).
}

Cadernos GPOSSHE On-line, Fortaleza, v. 5, n. 1, 2021 
pandemia, esses profissionais não conseguiam atender todas as demandas de interpretação, e os professores tiveram que lecionar sem a presença dos intérpretes. Nos grupos de Whats $A p$, priorizamos ${ }^{7}$ a comunicação em Libras e o uso de Português escrito em respeito aos surdos.

As ações foram desenvolvidas com a turma de sexta série do Ensino Fundamental II, que tinha onze alunos matriculados, mas apenas seis alunos estavam participando das aulas ativamente. Três alunos não dispunham de aparelho celular e dependiam da disponibilização do aparelho de algum integrante da família, devido à essa dificuldade, deixavam de participar e algumas vezes realizavam as atividades assíncronas; outros dois alunos mostravam um certo desinteresse nas aulas, pois ainda estavam em fase de aquisição da Libras. Aos poucos, estávamos tendo êxito no ensino remoto.

Para incentivar a participação dos alunos durante as aulas, optamos pelo uso exclusivo da Libras e de recursos visuais para a melhor aprendizagem dos discentes. As plataformas digitais usadas para ministrar as aulas foram: Zoom, Google Meet e Whats App por meio de chamadas de vídeo e de aulas assíncronas (aulas em vídeo anteriormente gravadas e editadas). Tivemos êxito na aprendizagem dos alunos graças à colaboração dos familiares, com os professores no uso da Libras como primeira língua e do Português escrito como segunda língua.

Para enfrentar os desafios impostos pela pandemia e solicitar a parceria das famílias, fizemos uma pesquisa com os alunos surdos e seus familiares, com o intuito de conhecer suas particularidades, socializar informações e, assim, estruturar melhor as ações da comunidade escolar. Buscamos saber como é a convivência dos pais com o filho surdo; expor a importância de não abandonar o aprendizado da Libra; pedir autorização para fazer registros fotográficos para futuros relatórios; combinar qual seria a frequência de encontros virtuais; manter contato com os alunos de forma virtual para demais orientações; apresentar o conteúdo que será abordado nas aulas e programar as atividades para cada semana, como atividades lúdicas, dinâmicas e jogos.

\footnotetext{
que houver informações advindas do relato de experiência.

Cadernos GPOSSHE On-line, Fortaleza, v. 5, n. 1, 2021

\author{
https://revistas.uece.br/index.php/CadernosdoGPOSSHE \\ DOI: $10.33241 /$ cadernosdogposshe.v5i1 \\ ISSN: $2595-7880$
}

${ }^{7}$ Pedimos licença ao leitor para utilizar o verbo na primeira pessoa do plural em alguns momentos do texto em 
Usamos recursos como: formulários online, imagens, vídeos no Youtube e escrita de sinais. Algumas atividades gravadas em Libras também foram passadas aos alunos. Em outros momentos, recomendamos vídeo no Youtube de poemas, contação de histórias e peças de teatro em Libras que tinham mais a ver com a cultura visual e depois discutimos sobre o vídeo assistido. Alguns alunos tinham dificuldade de acessar o Google Meet, então optamos por chamada de vídeo via Whats App para dar alguns avisos e orientações.

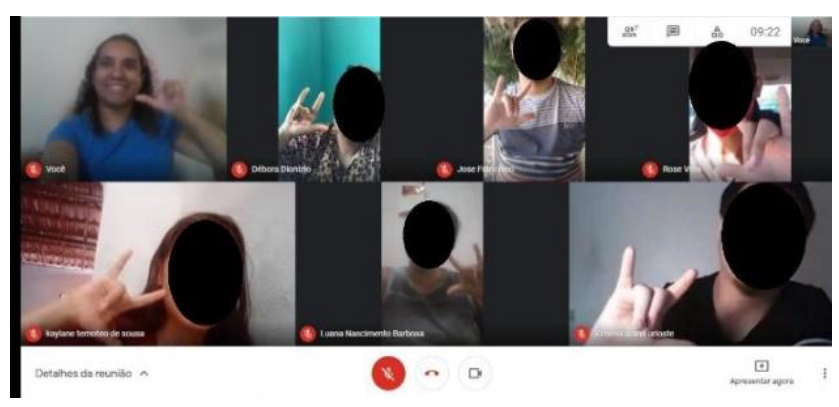

Figura 1: Aulas ministradas pelo Google Meet Fonte: acervo das autoras.

Durante a execução dessa pesquisa, observamos uma certa dificuldade de alguns alunos no uso das plataformas digitais, por isso, tivemos que apresentá-los a essas tecnologias até que se adaptassem. Os alunos que não tinham acesso à internet, buscavam as atividades impressas na escola e as devolviam depois de respondidas.

Em relação ao ensino de Língua Portuguesa, postamos aulas com a temática de vocabulário em vídeos no Youtube. Essa estratégia foi útil para alguns alunos que não possuíam aparelhos celulares e ficavam dependentes do celular de seus pais, que só chegavam em casa depois do trabalho, à noite.

Alguns alunos apresentavam dificuldades para enviar atividades em Libras, pois não sabiam enquadrar o vídeo corretamente, mas com algumas orientações isso logo foi resolvido.

\section{CONCLUSÃO}

Historicamente, o acesso e a permanência dos educandos com deficiência (especificamente, os surdos) na escola são dificultados por diversas formas de barreiras 
sociais. As conquistas legais e de garantia de políticas públicas são oriundas da organização e da luta principalmente desse público e de suas famílias.

Pela experiência do ICES, pode-se perceber que o ensino remoto colocou a comunidade escolar diante de muitos desafios. Para a equipe, gestores e professores, observou-se a urgência de reorganizar a forma de ensino; de adaptar-se às novas tecnologias com as devidas condições de organização, planejamento e formação para o ensino remoto. Observou-se que as condições de trabalho eram organizadas pelos próprios profissionais, sem auxílio imediato do Estado. Para os estudantes surdos, do sexto ano, observou-se que alguns não tinham acesso à internet; para outros, a única forma de acesso às aulas era através de um celular que pertencia a outro integrante da família, por isso, somente conseguiam ter acesso às aulas assíncronas.

Mesmo diante desses desafios, observou-se progresso na experiência do ensino remoto durante a Pandemia da COVID-19, visto que a comunidade escolar construiu um trabalho com o auxílio das Tecnologias de Informação e Comunicação (TIC) com o foco na aprendizagem dos alunos surdos. Buscou-se adquirir novos conhecimentos sobre essas tecnologias e logo essas atualizações eram repassadas para os alunos. Ressalta-se que toda a equipe aprendeu muito com os alunos, pois esses sempre compartilhavam conhecimentos que nós não tínhamos.

Houve avanços no uso de novos aplicativos e plataformas digitais em harmonia com os alunos. Os discentes surdos puderam mostrar várias habilidades durante a execução das atividades. A grande maioria dos alunos surdos conseguiram ter avanços na aquisição da Libras e do Português escrito, com exceção de dois alunos que ainda estavam se familiarizando com a Língua Portuguesa. O uso do Português escrito era mais usado em algumas atividades e em provas subjetivas. $\mathrm{O}$ uso intercalado de Libras e Português escrito foi importante para o apoio das famílias que não sabiam Libras e auxiliou os surdos a interagir nessa sociedade que se comunica majoritariamente em Língua Portuguesa.

Mesmo que tenhamos enfrentado alguns percalços no caminho, esse modelo de ensino desenvolvido juntamente com o aluno, professor, equipe pedagógica e família teve seus pontos positivos: conseguimos manter os alunos com suas atividades em dia, muito embora alguns tivessem que entregar suas atividades presencialmente. Também fizemos 
entrega de cestas básicas e de chips com acesso à internet aos alunos. A lição mais importante foi que durante a pandemia precisamos continuar com o ensino a distância até que tudo se normalize.

\section{Referências}

A Comissão Futuros da Educação da Unesco apela ao planejamento antecipado contra o aumento das desigualdades após a COVID-19. Unesco, 16 abr. 2020. Disponível em: https://pt.unesco.org/news/comissao-futuros-da-educacao-da-unesco-apela-aoplanejamento-antecipado-o-aumento-das Acesso em: 27 jul. 2021.

BRASIL. Constituição da República Federativa do Brasil. Brasília, DF, 05 out. 1988. Disponível em: http://www.planalto.gov.br/ccivil_03/constituicao/constituicao.htm. Acesso em: 27 ago. 2021.

BRASIL. Ministério da Saúde. Painel Coronavírus. Disponível em: https://covid.saude.gov.br. Acesso em: 02 ago. 2021.

BRASIL. Lei n 9.394, de 20 de dezembro de 1996. Estabelece as diretrizes e bases da educação nacional. Diário Oficial da União, Brasília, DF, 2005. Disponível em: http://www.planalto.gov.br/ccivil_03/leis/19394.htm. Acesso em: 28 ago. 2021.

BRASIL. Decreto $n^{\circ}$ 5.626, de 22 de dezembro de 2005. Regulamenta a Lei ${ }^{\circ} 10.436$, de 24 de abril de 2002. Dispõe sobre a Língua Brasileira de Sinais - Libras, e o art. 18 da Lei ${ }^{\circ}$ 10.098, de 19 de dezembro de 2000. Diário Oficial da União, Brasília, DF, 2005.

BRASIL. Lei n ${ }^{\circ}$ 10.436, de 24 de abril de 2002. Dispõe sobre a Língua Brasileira de Sinais Libras e dá outras providências. Diário Oficial da União, Brasília, DF, 2002. Disponível em: http://www.planalto.gov.br/ccivil_03/leis/2002/110436.htm. Acesso em: 27 jul. 2021.

BRASIL. Lei n ${ }^{\circ} 12.319$, de $1^{\circ}$ de setembro de 2010. Regulamenta a profissão de tradutor e Intérprete de Língua Brasileira de Sinais-LIBRAS. Diário Oficial da União, Brasília, DF, 2010. Disponível em: http://www.planalto.gov.br/ccivil_03/_ato2007-

2010/2010/lei/112319.htm. Acesso em: 27 jul. 2021.

BRASIL. Lei $\mathrm{n}^{\circ}$ de 10.098, de 19 de dezembro de 2000. Estabelece normas gerais e critérios básicos para a promoção da acessibilidade das pessoas portadoras de deficiência ou com mobilidade reduzida, e dá outras providências. Diário Oficial da União, Brasilia, DF, 2000. Disponível em: http://www.planalto.gov.br/ccivil_03/leis/110098.htm. Acesso em: 27 jul. 2021. 
BEHRING, Elaine. Fundamentos de Política Social. In: MOTA, A. E. et al. (orgs.). Serviço Social e Saúde: Formação e Trabalho Profissional. São Paulo: Cortez, 2006.

CUNHA, Ana. Deficiência como expressão da questão social. Serviço Social \& Sociedade, São Paulo, n. 141, p. 303-321, maio/ago. 2021.

DAMASCENO, João Carlos Bittencourt; ASSUMPÇÃO, Douglas Junio Fernandes. Uma reflexão da educação especial a partir das políticas públicas educacionais brasileiras.

Revista@mbienteeducação, v. 13, n. 2, p. 216-231, 2020.

FERNANDES, Sueli; MOREIRA, Laura Ceretta. Políticas de educação bilíngue para surdos: o contexto brasileiro. Educar em Revista, p. 51-69, 2014.

IAMAMOTO, Marilda. A questão social no capitalismo. Temporalis, Rio de Janeiro: ABEPSS, n. 3, ano 2, jan./jun. 2001.

IAMAMOTO, Marilda. Mundialização do capital, "questão social" e Serviço Social no Brasil. Revista Em Pauta: teoria social e realidade contemporânea, n. 21, p. 117-140, 2008.

INSTITUTO Cearense de Educação de Surdos comemora 55 anos com alunos e exalunos. Secretaria de Educação do Ceará, Ceará, 04 abr. 2016. Disponível em: https://www.seduc.ce.gov.br/2016/04/04/ices-comemora-seus-55-anos-com-mais-de150-alunos-e-ex-alunos-surdos/. Acesso em: 10 ago. 2021.

KASSAR, Mônica. Educação especial na perspectiva da educação inclusiva: desafios da implantação de uma política nacional. Educar em Revista, Curitiba, Brasil, n. 41, p. 61-79, jul./set. 2011.

LACERDA, Cristina. Um pouco da história das diferentes abordagens na educação dos surdos. Cadernos Cedes, v. 19, n. 46, p. 68-80, 1998.

MAIOR, Izabel. História, conceito e tipos de deficiência. In: Textos de apoio. Programa Estadual de Prevenção e Combate à violência contra as pessoas com deficiência. São Paulo: Secretaria de Estado dos Direitos da Pessoa com Deficiência, 2015. Disponível em: http://violenciaedeficiencia.sedpcd.sp.gov.br/pdf/textosApoio/Texto1.pdf. Acesso em: 4 set. 2021.

NEVES, Lidia. Saiba o que é lockdown. Ou: por que suspender atividades. [S. l.], 17 mar. 2020. Disponível em: https://coronavirus.ufes.br/conteudo/saiba-o-que-e-lockdownou-por-que-suspender-atividades. Acesso em: 3 ago. 2021.

ORGANIZAÇÃO MUNDIAL DA SAÚDE. Recomendações sobre o uso de máscaras no contexto da COVID-19. Orientações provisórias, 5 de junho de 2020. 
Disponível em: https://apps.who.int/iris/bitstream/handle/10665/332293/WHO-2019nCov-IPC_Masks-2020.4-por.pdf. Acesso em: 4 ago. 2021.

SOUZA, Pedro. Educação de surdos no brasil: uma narrativa histórica. Anais $\mathbf{V}$

CONEDU. Campina Grande: Realize Editora, 2018. Disponível em:

http://www.editorarealize.com.br/index.php/artigo/visualizar/47071. Acesso em: 31 jul. 2021.

STROBEL, Karin Lilian. A visão histórica da in (ex) clusão dos surdos nas escolas. ETDEducação Temática Digital, v. 7, n. 2, p. 245-254, jun. 2006.

VARELA, Renata Cristina Bertolozzi; OLIVER, Fátima Corrêa. A utilização de Tecnologia Assistiva na vida cotidiana de crianças com deficiência. Ciência \& Saúde Coletiva, v. 18, p. 1773-1784, 2013.

Trabalho oriundo do I Seminário do GPOSSHE - Educação do campo e Pedagogia bistórico-crítica em contexto de crise e pandemia 